\title{
Will this COVID-19 wave be a tsunami for surgery?
}

The views expressed in this editorial are those of the author and do not necessarily reflect the position of the Canadian Medical Association or its subsidiaries.

W e seemed to almost have this pandemic thing figured out. Canada was ahead of much of the world in vaccination. We seemed to be okay with continued social distancing and masks. Even vaccination passport policy appeared to be accepted by the majority to allow greater access to indoor venues. But we may have been too fast with raised expectations. The fourth wave of COVID-19 we had been hearing might happen has arrived.

Canada's chief public health officer reported that national surveillance data indicate that a fourth wave is underway in Canada and that cases are tracking at an increasing rate in certain regions: the 7-day average as of Sept. 29 is 4358 cases per day, which is back up to levels seen in May 2021. ${ }^{1}$ This is certainly not the downturn in cases we anticipated. The delta variant is currently driving the resurgence, with the sickest patients coming from among the unvaccinated. It seems to have a higher infectivity than previous variants.

Regardless of the anti-vaccination advocates' claims, health care resources are being used up by this resurgence. Intensive care unit and hospital beds are now occupied by unvaccinated patients with COVID-19. Resources are also restricted by burnout among health care providers, including ancillary staff. This burnout has been exacerbated by the absence of human resources personnel who were sent home during the pandemic; normal turnover of staff necessitates constant hiring - a process put to bed because of the pandemic.

Ignoring the situation has been unsuccessful. Alberta's earlier reopening of infrastructure and services without social distancing measures or vaccination passports is a unique example, and their extreme shortages in health care are seen as a dire warning against such an approach. Ontario has abandoned early opening to add more controls to hopefully abort the fourth wave.

Elective surgical cases are on hold or severely limited in most provinces. Extremity surgery, hernia repair and bariatric surgery are at a standstill. The lists of patients waiting for these procedures were already ballooning and will be further delayed. Prioritization of cancer surgery is still occurring, and other limb- or life-threatening surgeries are being performed at a slightly slower rate. What do we do with the walking or stretcher-ridden patients with diagnoses like fractures or acute vascular insufficiencies? Mortality and morbidity are well documented for these patients if they do not receive surgery in a timely fashion. But we are now rationing their care directly or indirectly through bed shortages.

Governments are waking up to the risks. In 2021, the Financial Accountability Office of Ontario estimates that addressing surgery backlogs created by the pandemic will cost $\$ 1.3$ billion. $^{2}$ Ontario has budgeted $\$ 610$ million to address the needs, but the Financial Accountability Office report admits there is a funding shortfall. ${ }^{2}$ Some more money is to be brought to bear for critical tests and some elective surgeries high on the priority lists, but we are in a situation of almost complete patient neglect. There needs to be a national agreement - driven by surgeons - on what we do to ensure patient care is not completely subverted. Provincial governments will need to sign on and carry out the plan, which will likely take more than 5 years to complete - longer than most political mandates. We need to address the shortcomings of the current situation and the conditions that came before to exact meaningful change in the care of our patients. If we don't do it soon, we will all be in trouble.

\section{Edward J. Harvey, MD, MSc}

Coeditor, Canadian fournal of Surgery

Competing interests: E.J. Harvey is the cofounder and head of medical innovation of NXTSens Inc.; the cofounder and chief medical officer of MY01 Inc., and Sensia Diagnostics Inc.; and the cofounder and director of Strathera Inc. He receives institutional support from J \& J DePuy Synthes, Stryker, MY01, and Zimmer.

Content licence: This is an Open Access article distributed in accordance with the terms of the Creative Commons Attribution (CC BYNC-ND 4.0) licence, which permits use, distribution and reproduction in any medium, provided that the original publication is properly cited, the use is noncommercial (i.e., research or educational use), and no modifications or adaptations are made. See: https://creativecommons. org/licenses/by-nc-nd/4.0/

Cite as: Can J Surg 2021 October 26; 64(5). doi: 10.1503/cjs.017321

\section{References}

1. COVID cases in Canada tracker: how many new cases of COVID-19 today? Global News 2020 Mar. 9 [updated 2021 Oct. 6]. Available: https://globalnews.ca/news/6649164/canada-coronavirus-cases/ (accessed 2021 Oct. 6).

2. Financial Accountability Office of Ontario. Ministry of Health 2021 spending plan review. FAO; 2021. Available: https://www.fao-on.org/ web/default/files/publications/FA2 101-1\%20Health\%20Estimates/ Health\%20Spending\%20Plan\%20Review\%20Presentation-EN.pdf (accessed 2021 Oct. 1). 